\title{
The Actors' Renaissance Season at the Blackfriars Playhouse
}

\section{Introduction}

In 2001, the Blackfriars Playhouse opened in Staunton, Virginia, and became the permanent home for Shenandoah Shakespeare (S2), the touring company co-founded in 1988 by Professor Ralph Alan Cohen and Jim Warren, under the name Shenandoah Shakespeare Express. The reconstruction project drew on the advice of among others) Professor Andrew Gurr, one of the chief academic advisors to the Shakespeare's Globe project on Bankside. The advent of the Blackfriars allowed S2 to produce a season of predominantly Shakespearean titles performed by a resident company of actors between June and December, whilst continuing their touring operations with a second troupe, whose contracts culminated in a short Spring residency at the Blackfriars. The company's best-selling promotional bumper sticker proclaims 'We Do It With The Lights On,' referring to the 'original practice' of performing Shakespeare's plays under universal lighting conditions. The company's pre-show announcements also emphasise the importance of other 'original practices,' including the use of a doubling scheme, continuous staging, and direct audience address.

In 2005, now as the American Shakespeare Center (ASC), the company took the 'original practices' brief to a new level, launching the Actors' Renaissance Season in the Blackfriars' 3-month 'off' season between January and March. Conceived as a kind of experiment with early modern rehearsal methods, the details of which are discussed below, the Actors' Renaissance Season would both develop the ASC's existing commitment to 'original practices' and make them a year-round operation. With Shakespearean titles 
dominating the season planning for both the resident company and touring troupe, the addition of the Actors' Renaissance Season also presented an ideal opportunity to introduce more non-Shakespearean early modern titles into the ASC's season planning overall ${ }^{1}$. It is with the plays of Shakespeare's contemporaries that this chapter is primarily concerned. The first Actors' Renaissance Season offered The Tamer Tamed (in repertory with The Taming of the Shrew) as well as A King and No King. The Actors' Renaissance Season offerings since 2005 have included some Shakespearean fare (the Q1 Hamlet and Pericles, as well as the more frequently produced Macbeth and A Midsummer Night's Dream) but also popular productions of 'Tis Pity She's a Whore, Eastward Ho!, The Duchess of Malfi, The Devil is an Ass, Volpone, The Jew of Malta, The Revenger's Tragedy, The Changeling, and The Blind Beggar of Alexandria, to name but nine.

The Actors' Renaissance Season is arguably the most stringent of the ASC's many experiments with the concept of original practices, using a rehearsal format that includes memorisation of 'parts' followed by brief group rehearsals without a director. In both format and methodology, the Actors' Renaissance Season approach is shaped by the work of scholars, rather than practitioners. The largest debt is owed to the work of Tiffany Stern, particularly Making Shakespeare (2004), excerpts of which are reproduced in a handbook drawn up by the ASC and circulated to actors under contract in the Actors' Renaissance Season. The first section of this chapter explores some of the implications of this particular document's fusion of academic, creative and commercial interests.

\footnotetext{
${ }^{1}$ The Education department of the ASC occasionally holds playreadings in the Blackfriars - the 'Bring 'Em Back Alive' series - in which plays by lesser-known early modern playwrights are read by volunteers from the wider Staunton community. The readings, which take place at irregular intervals, are distinct from the commercial operations of the resident, touring, and Actors' Renaissance Season troupes, and are not an integral part of the Education department's programming for Virginia schools, which necessarily reflects the content of the school curriculum.
} 
The Actors' Renaissance Season's methodological roots in Early Modern scholarship ${ }^{2}$ mean that its productions have attracted a good deal of scholarly interest. Every two years, the ASC hosts the Blackfriars Conference, featuring (among many other things) a special session on the findings from the Actor's Renaissance Season. The Actors' Renaissance Season thus feeds into, and feeds from, current research into early modern stage practices. It inflects curriculum development and teaching practice too, as Professor Cohen is also the co-founder (with Professor Frank Southerington) of the MLitt/MFA programme in Shakespeare and Renaissance Literature in Performance. This partnership between ASC and Mary Baldwin College coincided with the opening of the Blackfriars in 2001, and emphasises Early Modern original stage practices in teaching and performing early modern drama. As the director of several ASC resident and touring company productions, and the head of the Mary Baldwin MFA acting, directing and dramaturgy programs from 2004-2009, I was ideally positioned to observe developments in this partnership from many angles.

Economic no less than academic arguments might recommend the Actors' Renaissance Season model of producing plays to the ASC management in the post-recession climate. As well as saving the costs involved with hiring an in-house or guest director and designer, the short rehearsals associated with the Actors' Renaissance Season save on actor salaries, too. Much of the crucial work an actor puts into these productions will happen in isolated private study of their own 'part' - that is, their lines, and short cue-lines only - long before the start of the expedited group rehearsals. This chapter's chief concern is to consider how memorization from parts, expedited group rehearsals, and the absence of a

\footnotetext{
${ }^{2}$ Andrew Gurr's work as an academic and key advisor to the Globe project underpins ASC policy on 'original' stage practices, as well as curriculum development in the MLitt/MFA programme at Mary Baldwin College. Patrick Tucker's approach to rehearsal and staging (for the Original Shakespeare Company) is also acknowledged as influential, and may be found in his Secrets of acting Shakespeare: the original approach (New York: Routledge, 2002).
} 
designated director all inflect these actors' approaches to characterisation at the ASC. I argue that the relative unfamiliarity of the non-Shakespearean titles means that the actors tend to focus the little time they have in group rehearsals on such fundamental elements as narrative clarity and basic staging. With very little time left for nuanced character development, actors tend to develop a recyclable series of broad-stroke characterisations, as part of a collective technical shorthand. The chapter will show how this collective shorthand draws on both the ensemble's cumulative training backgrounds and their shared experience of playing the Blackfriars space.

As scholarly debates and discussions about Early Modern 'original stage practices' have tended to emphasise the phenomena of audience and architecture, the role played by modern actor training methods, used by modern actors working in the reconstructed early modern theatre spaces, has been largely overlooked. Though the absence of a designated director is certainly an interesting element of the Actors' Renaissance Season, directing in itself is hard to define in a comprehensive one-size-fits-all way, making it difficult to draw any meaningful conclusions about the real difference a director's absence makes. What can be demonstrated, though, are the ways in which modern performance methodologies can mesh with research into early modern stage practices, enabling actors in the Actors' Renaissance Season to mount productions of both popular and less familiar early modern plays quickly and cost-effectively, for a steadily growing audience of academics, students and enthusiasts.

The Actors' Renaissance Season handbook: the rules of engagement and who does what All of the 'rules' governing the Actors' Renaissance Season are set out in a handbook that the ASC provides for each of the actors upon signing a contract. In it, the ASC set out 
rigorously-stated 'rules of engagement' with early modern performance, in an approach to staging that privileges individual study over group rehearsal as a dominant mode. In what is possibly an unprecedented innovation, the ASC also requires actors new to the Actors' Renaissance Season to read Stern's Making Shakespeare, provided to them along with the contract and the handbook, which describes Making Shakespeare as the 'guidebook for the Renaissance Season (but not necessarily the rulebook). ${ }^{3}$ The Actors' Renaissance Season troupe lacks a director, but not a hierarchy of sorts. Jay McClure, the ASC Associate Artistic Director, is largely responsible for the process of inviting (rather than auditioning) between 10 and 12 actors, who adopt the early modern nomenclature of 'Sharers, ${ }^{4}$ to participate in the season. Only actors with considerable experience of the space are considered for a Sharers contract. As a result, the Actors' Renaissance Season company has a slower turnover rate than either the resident or touring troupe, and the Actors' Renaissance Season Sharers tend to know each other very well. The rationale for not holding open auditions is therefore both economic and pragmatic; as suggested above, the work of the Sharers in the Actors' Renaissance Season draws on a pre-existing shared vocabulary and so shortcuts can be taken to expedite the process of preparing the show. Currently, the Sharers are contractually responsible for the preparation and performance run of five plays over three months.

Other actors, identified as 'Apprentices' in another nod to early modern company infrastructure, are drawn from the partnership MLitt/MFA programme at Mary Baldwin College and the local Staunton community, via audition. Apprentices typically fill out the smaller roles in any given play. The numbers of Apprentices hired each season varies,

\footnotetext{
${ }^{3}$ ASC Handbook, reprinted in McCarthy Ryan, 'A Brief Introduction to Practical Dramaturgy,' unpublished M.F.A thesis, Mary Baldwin College, 2008, 2.

${ }^{4}$ For a detailed discussion of early modern companies see Andrew Gurr, The Shakespearian Playing Companies (Oxford University Press 2006).
} 
depending on casting needs. Sharers notionally have responsibility for 'individual instruction,' that is, mentoring and supervising the work of the student Apprentices, but in practice there is little time for any formal training in technique. The experience of performing in the company is regarded as its own instruction; indeed, Apprentices drawn from the Mary Baldwin College MLitt/MFA programme typically identify participation in the Actors' Renaissance Season as one of the highlights of their academic career at the College. Sharers are charged collectively with facilitating scene, music and fight preparation for each production. Specific division of labour is not formally set out in the contract, reflecting the ASC's wider policy which values all-rounders over specialists. In practice, however, it often falls to the actor with the most lines for a particular production to provide a lead in shaping the details of rehearsal format and schedule. Working under sometimes extreme time constraints - The Jew of Malta (2008) rehearsed for a total of fifty-five hours - a collaborative approach to the work in hand is invaluable. ${ }^{5}$ In addition to those 'leading' actors identified above, other Sharers not playing an active part in a particular scene will serve as 'outside eyes' for those in the scene, offering the kind of feedback perhaps normally associated with a director. Such feedback is a welcome and recognised part of the process. With stage time at a premium and different scenes being rehearsed simultaneously in three locations within the theatre (the stage, a rehearsal space in the basement below the stage and the upper lobby) many scenes are lucky to get more than one run through on stage, so the surrogate-directorial perspective is a vital one to this process.

The hitherto vexed role of the director within the framework of 'original practices' is therefore not banished from the Actors' Renaissance Season, but multiplied by the number of Sharers taking a kind of collective responsibility for some traditionally directorial

\footnotetext{
${ }^{5}$ McCarthy, 'Brief Introduction,' 3.
} 
functions. The webpage for the 2008 Actors' Renaissance Season describes a process of 'cutting out the directors, designers, and the months of rehearsals that Shakespeare's company never knew,' implying that such decadence is not only commonplace in modern theatre productions of early modern plays, but also something that the ASC itself has tried at some point in its history. ${ }^{6}$ Though production support for other parts of the ASC season is actually minimal by most industry standards, ${ }^{7}$ the emphasis on a kind of unfettered approach to performance is nonetheless proving an effective marketing tool.

The handbook also suggests that amongst the duties assigned to Sharers may also be tasks normally associated with company or stage management, such as housing coordination and wardrobe management. A pivotal stage managerial presence may be found in the Prompter, identified on a production-by-production basis, usually from the ranks of the Apprentices. Prompters are responsible for maintaining a copy of the performance script, reflecting changes to individual actors' parts made during rehearsals, in a 'master copy' of the performance script. The Prompter may also facilitate group scene rehearsals and cue actors for entrances and lines during each group rehearsal. S/he sits backstage during performances, waiting to prompt any actor who calls for a line. An Apprentice who serves as Prompter for a particular production will not perform in that production under normal circumstances, but with no formal understudy rehearsals possible in the time allowed for the Actors' Renaissance Season plays, the Prompter must also agree to go on for an actor in the case of an emergency.

\footnotetext{
${ }^{6}$ American Shakespeare Center, Actors Renaissance Season Opens, 9 Jan. 2008, last accessed 6 July 2011 $<$ http://tinyurl.com/AmericanShakespeare>.

${ }^{7}$ ASC resident and touring company productions (which do use directors) have recently reduced their rehearsal periods from three and a half to just two weeks, and one or two designers make all the costumes for each season of plays.
} 
In each instance, the Prompter is working from the sole complete copy of the performance script. In the first few Actors' Renaissance Seasons, the task of preparing this prompt script was undertaken by Apprentices or by other students from the MLitt/MFA programme, for example those enrolled in the 'Shakespeare's Contemporaries' class at the time. The preparation involves cutting the script into the promptbook version before dividing it into parts, by role. Sharers and Apprentices are thus provided with parts, rather than complete scripts. A cue of three or four words is provided before each speech, but little else in the way of context is provided prior to rehearsals. Like many other conventions followed in the Actors' Renaissance Season, the process of dividing the script into parts finds its provenance in Stern's Making Shakespeare, in which Stern provides clear practical motivations for this early modern practice. Since parts had to be written out by hand by a scribe, dividing a single handwritten script into parts (rather than providing each actor with a complete script) saved a considerable amount of time, ink and paper. Limiting the number of complete copies of the script in circulation also minimised the risk of a printer getting hold of one. ${ }^{8}$ These days, of course, the situation is very different: one might speculate that when the Actors' Renaissance Season mounts a play by Shakespeare, actors wishing to memorise their lines exclusively from parts have to consciously unlearn what they might already know about the play and consciously avoid coming into contact with multiple editions of the complete scripts currently in circulation.

Since 2009, Sharers have opted to take on the responsibility for preparing the prompt or performance script. These actors therefore have sight of a full, uncut version of the script, from which they prepare the promptbook copy, while the remainder of the company have access only to their parts. When I interviewed him, ASC veteran actor John

\footnotetext{
${ }^{8}$ Stern, Tiffany, Making Shakespeare: From Stage to Page (New York: Routledge, 2004) 124.
} 
Harrell described the increasingly fluid nature of the prompt scripts used in Actors'

Renaissance Season productions. Harrell referred to the parts as 'sides,' a modern term that can include, but is not limited to, the 'part' as defined by Stern and others: ${ }^{9}$

Actors are free to make further cuts once they have their sides. They can also, if they like, go back to an uncut text and stick a line back in. The only ironclad rule in any of these cases is that any change must be copied into the prompt book, because we actually use an onstage prompter and he or she needs an accurate text. ${ }^{10}$

Added to the freedom to consult 'outside' texts described above, further modifications to the exercise in learning from parts surely come into effect when the play chosen is a wellknown Shakespearean title (e.g. Macbeth in 2008). In these instances, the difference between learning lines from 'parts' and the more usual method - by memorising lines and cues picked out with a highlighter pen from a full script - is arguably minimised. Whatever the level of familiarity with the plays prior to receiving their parts, Sharers feel a responsibility to memorise as many of their lines as possible before the season begins Typically this results in Sharers being off book for those plays in which they have larger roles, as well as those which open the season. The last of the Actors' Renaissance Season productions to open may begin its short rehearsal period with fewer actors off book.

Parts and passions, objectives and actions: different approaches to characterisation

\footnotetext{
9 "Side" is the common term used to describe a script excerpt used for audition purposes, lifted wholesale from the play. Sides differ from "parts" in their inclusion of the chosen excerpt in full, so that the actor auditioning is aware not just of their own lines, but of any lines spoken by others in the same excerpt.

${ }^{10}$ Harrell, John, Personal interview, Oct. 2010.
} 
It is therefore in the weeks leading up to the start of group rehearsals that Sharers and Apprentices put many of the basic elements of characterisation in place without the benefit of group rehearsal to inform this process. Potential challenges to 'received' theatre practice in general (and characterisation processes in particular) can arise if the actors are largely unfamiliar with the play prior to receiving their parts and they do not resort to consulting uncut versions of the text. In textual terms, all that the actors working from parts 'know' about their characters is what can be gleaned from what they say about themselves, or how they speak to others. What others say of the character will be unknown to them, prior to the first read-through.

The Actors' Renaissance Season contract and rules of engagement privilege discoveries made during private study over ensemble approaches to storytelling born out of group rehearsal. They do so by quoting Stern's Making Shakespeare on the subject in the ASC Handbook:

Trying to sort out how to perform their 'part' well, actors in Shakespeare's day were not primarily concerned with the story they were telling. Instead they were looking inwards at their parts, determining what the emotions required by their roles were, and how best to manifest them using gesture and pronunciation.

Which 'passion' was being exhibited, and at what moment, was easily identifiable in a part and so was seen to be one of the most important aspects of acting; a term often used to describe the art of acting at the time was 'passionating'...'Passion' was 
not the vague word then that it is now. 'The passions' were the emotional extremes. $^{11}$

What is remarkable here is the double emphasis on private study and emotion over ensemble approaches to narrative clarity and action as the root of a performance. In these two respects, what Stern is identifying here is radically at odds with most modern performance practice. Though modern casting practices can at times seem more feudal than democratic - brutal terms like 'leading actor' and 'minor role' are bandied around without so much as an institutional blush - most US and UK theatre professionals in the post-Brook era acknowledge in some way the supposedly collaborative process of theatre-making on some level. ${ }^{12}$ Where directors build 'table work' into the early stages of rehearsal (as most directors of early modern scripts still do), this process of close reading, discussion and textual analysis of some kind is more often than not regarded as a group or even fullcompany activity, one which seeks to incorporate the various individuals' preparation processes into a cohesive whole.

'Emotion' in itself is not the principal unit of modern performance, though it may be the element most easily identifiable by modern audiences. Since its inception, Stanislavski's 'system,' as described by Roberta Barker (XXX-XXX in this volume), has been endlessly modified and incorporated into a wide variety of approaches to actor training. Yet its clear principle of action still underpins the way most modern actors engage in private study of a script. Actors still tend read for objectives ('what do I want?') leading to actions ('how am I going to get it?'). This way of reading will identify an 'emotion' as something that emerges

\footnotetext{
${ }^{11}$ Stern, Making Shakespeare, 79-80, reprinted in McCarthy, 'Brief Introduction,' 32.

${ }^{12}$ One example of the perceived value of the 'ensemble' is the RSC's Ensemble contract under Michael Boyd, currently central to that institution's mission; see Coen Heijes' discussion of Boyd's approach in this volume (XXX-XXX).
} 
out of a process of performing specific actions with a specific objective in mind, within the 'given circumstances' of the scene; emotion is therefore not a formalistic repeatable gesture or a condition with a specific, legible form. Emotion is in fact a loaded term within many actor training regimes, and inexperienced actors may find themselves criticised for appearing to 'play the emotion' rather than the action. While Stern and Palfrey argue that for the early modern actor 'a semantic opposition was drawn at the time between "action" and "passion": "action" was physiologically the externalization (acting) of internal feeling (passion),' the majority of modern actors in the US and UK have been trained within a system that locates emotion as the externally recognisable result of an internal or external action, stemming from an internal need. ${ }^{13}$ Emotions are therefore (important) theatrical products or effects, not forms, in most post-Stanislavskian methodologies. ${ }^{14}$

So, in adopting Stern's emphasis on 'passion' as the definitive element through which individual performances are mediated and orchestrated in private, the handbook for Actors' Renaissance Season reflects the extent to which actor training methodologies may have changed over 400 years. It also suggests that participation in the season might require, or result in, a re-evaluation of the actor's job description. Chiefly, it emphasises what the actor working from a part does not have, namely, a designated director or a working knowledge of the whole script. But as my concern in this chapter is primarily with actors' approaches to characterisation, I will next examine some actors' responses to what they do have: the information contained in the part itself.

\section{Close reading, commedia, 'character lists' and embedded stage directions}

\footnotetext{
${ }^{13}$ Palfrey, Simon and Stern, Shakespeare in Parts (Oxford: Oxford University Press, 2007) 313.

${ }^{14}$ For a more detailed discussion of the relationship between action and emotion in modern theatre practice, see Alfreds, Mike, Different Every Night: Freeing the Actor (London: Nick Hern Books, 2007).
} 
Private study of a part leads many modern actors to draw on their experience and training to delineate character from the evidence in the part, using a combination of scholarship and practice. As Chris Johnston, an ASC and Actors' Renaissance Season veteran, told me in an interview, when reading a part,

Training in stock characters, like commedia, is really helpful. Certain playwrights will give you a huge clue as to who your character is just by name of the character...Names like Ambitioso, Vindici really help out find who the character is. Middleton isn't the only one who does this. It pops up everywhere. In Heywood's $A$ Fair Maid of the West (or A Girl Worth Gold) you have the character Goodlack, and in Ben Jonson's Alchemist, it's almost every character, Face, Subtle, Puss Pliant etc. These names, combined with an understanding of stock characters, help when you are handed a cue script with only your lines. There will always be the shoes of a lover, a clown, a melancholic, a villain to fill in each of these plays. Once I've identified what my name may mean, and what 'shoes' I'm wearing, I'm at a really good place to start colouring the role. ${ }^{15}$

The ability to recognise 'patterns in the wallpaper' of stock characters is obviously a useful skill and for some it may seem an adequate substitute for group rehearsal. But Johnston explains that for him, establishing type - here the appropriate physical archetype from the commedia dell-arte - is the foundation of, rather than a substitution for, the application of technique. His method of preparing a part also reflects the broad church of post-Stanislavski

\footnotetext{
${ }^{15}$ Johnston, Chris, Personal interview, Oct. 2010.
} 
actor training common to most conservatories and drama departments across America. Johnston looks next for 'relationships, where the story leads, what I say about certain characters and what they may say about me. ${ }^{16}$

Johnston refers here to a kind of context-gathering exercise common to many postStanislavski approaches to characterisation and labelled by some as 'character lists.' Actors making these lists might collect all the quotations from the play that show (a) what their character says about her/himself, (b) what s/he says about others, and (c) what others say about her/him. ${ }^{17}$ Johnston's comments also remind us that roles are not typically played in isolation and that the actions played by others will crucially inflect characterisation. The modern methodology he adopts reflects an assumption that what other characters say about his character may be as important to the overall narrative as what he says about himself. But parts modelled after early modern examples which contained 'all the words the actor was going to speak, but nothing that would be said to or about him' will not include the information under item (c). ${ }^{18}$ This information can only be deduced once group rehearsals begin.

\section{Group rehearsals for The Jew Of Malta (2008)}

For each production in the Actors' Renaissance Season, the company begin the first day of group rehearsals with a read-through, assisted by the Prompter. Many actors glean vital information about narrative development and characterisation from this reading, because it is the first time that the company and parts are (re)assembled. A great deal of

\footnotetext{
16 Johnston, Personal interview, 2010.

${ }^{17}$ For a full discussion of the 'Character Lists,' see Alfreds, Different Every Night, 206-23.

${ }^{18}$ Palfrey and Stern, Shakespeare in Parts, 1.
} 
basic contextual information emerges that cannot be gleaned from individual sides in isolation.

McCarthy provides a good illustration of how individual parts speak to each other in his account of the 2008 Actors' Renaissance Season production of The Jew of Malta. He notes how ASC actors Alyssa Wilmoth (AW) and John Harrell (JH) absorbed embedded stage directions and clues to visual characterisation contained in each other's parts, during the first read-through of the assembled company (and parts):

Following Ithamore's line, 'I know she is a courtesan by her attire,' AW said 'Direction from beyond the grave.' She realized immediately that she would have to choose a costume that made her occupation readily apparent. Similarly, when Abigail said 'Why, how now, Ithamore, why laugh'st thou so,' JH began laughing and made a note in his script to start laughing before the line. ${ }^{19}$

As mentioned above, the Actors' Renaissance Season rules of engagement mean that actors costume themselves, pulling from stock, and not everyone waits until the first read through to start this process. James Keegan, who played Barabas in the same production, describes to McCarthy how his character's appearance suggested itself before the period of private study even began, based on some simple, practical considerations:

When I go to pull a costume, I sort of know where I'm going and I know what's there. I know the history of certain costumes and I know who's worn them, and that feels like being at home. And there's no substitute for feeling like you're at home, when

${ }^{19}$ McCarthy, 'Brief Introduction,' 4 
you're doing something that's this seat of your pants. I came to see Love's Labors [sic] Lost in the Summer/Fall Season, and I was watching Rene Thornton Jr. onstage as Navarre, and I said 'That's my Jew costume.' I knew it would fit me and how it would look, so that was chosen ahead of time. And that was great, because I knew that as long as it got back from the dry cleaners on time, I didn't have to pull anything. ${ }^{20}$

Keegan's well-chosen metaphor reveals not just a kind of sartorial shortcut available to the 'old hands' in the company. The notion of recycled clothing on the early modern stage is one that informed Jenny Tiramani's work as Master of Clothing and Properties at Shakespeare's Globe. The comments also betray the intimacy of the Actors' Renaissance Season Sharers, some of whom (to use another sartorial metaphor) live in each others' pockets for a good portion of the year. McCarthy notes that this factor compromises the quasi-scientific time element of the Actors' Renaissance Season 'experiment,' making it difficult to assess how the production develops, and when:

Many of the actors not only work together, but also live together in housing provided by the ASC. Any group of people working so intensively naturally discusses that work even during their time off. Not only that, but actors find time to rehearse outside of the scheduled times. ${ }^{21}$

\footnotetext{
${ }^{20}$ Keegan, James, Interview with McCarthy in 2008, 'Brief Introduction,' 15.

${ }^{21}$ Ibid., 2.
} 
Where rehearsal schedules are fully documented in print - as is the case for The Jew of Malta (2008) - the evidence suggests that after the first read-through, much of the remaining time will emphasise basic staging.

\section{Staging priorities, embedded entrances and meaningful exits}

The ASC Handbook reinforces the importance of approximating early modern stagecraft, encouraging actors to follow stage directions embedded within individual parts and requiring that

entrances and exits will be made from the center opening or flanking stage-doors. Action will remain on the stage platform (unless audience entrances are called for in the text). The balcony, trap, or heavens will be used only if called for in the text. ${ }^{22}$

In practice, the heavens have been used only once, restricted more by health and safety regulations than by the rules of original stage practices. Actors identify and fix entrances and exits as quickly as they possibly can. After the initial group read-through, the company for The Jew of Malta rehearsed the musical interludes for an hour and then addressed entrances and exits in a group rehearsal for Act 1, scene 1:

Most of the work involves determining when to enter. Edited texts tend to include entrances slightly too late. For instance, the script indicates that three Jews enter after Barabas says, 'But who comes here?' The actors then have to determine what the actual cue will be so that JK [James Keegan] has something to react to, like the

\footnotetext{
${ }^{22}$ American Shakespeare Center handbook, reprinted in McCarthy, 'Brief Introduction,' 32.
} 
opening of a door, that prompts him to inquire 'who comes here?' Because the scene involves a series of people coming to visit Barabas, the blocking remains fairly simple. Everyone involved is satisfied with the state of 1.1 within twenty minutes. ${ }^{23}$

McCarthy's account of this rehearsal suggests that knowing when to enter and when to exit is the primary concern for actors working from cue scripts. With comparatively little time to rehearse, the actors' concern to avoid one of the undisputed hallmarks of an underrehearsed production, that is, confusion and delays caused by late or incorrect entrances and exits, is not altogether surprising. Less apparent, perhaps, is the way in which narrative clarity is served by this approach. With little or no group rehearsal time available for the clarification or refinement of specific performance objectives within the scene - another way to achieve narrative clarity - the actors can still use the space itself in service of the narrative. The Blackfriars' two flanking doors and central discovery space offer the possibility of investing certain areas of the stage with various imagined locales and actors familiar with the space will often decide that, for instance, one flanking door should be used for all 'interior' entrances and exits, with the other for 'exterior' entrances and exits only. ${ }^{24}$ This convention, adopted in the interest of consistency and narrative clarity, relates primarily to the architectural forms of the Blackfriars space, but formal conventions associated with performance style may also be given consideration.

\footnotetext{
${ }^{23}$ McCarthy, 'Brief Introduction,' 4.

${ }^{24}$ On stage doors, see Fitzpatrick, Tim, 'Spaces, Doors, and Places in Early Modern English Staging,' Theatre Notebook 63.1 (2009): 2-20; see also Fitzpatrick's 'Shakespeare's Exploitation of a Two-door Stage: Macbeth,' Theatre Research International 20.3 (1995): 207-30; 'Playwrights with Foresight: Staging Resources in the Elizabethan Playhouses,' Theatre Notebook 56.2 (2002): 85-116; and, with W. Millyard, 'Hangings, Doors and Discoveries: Conflicting Evidence or Problematical Assumptions?' Theatre Notebook 54.1 (2000): 2-23.
} 


\section{Talking to the audience: asides, forms and transactions}

The Blackfriars' open space and universal lighting also mean that special attention should be paid to the playing of 'asides.' I use this term with caution, because in a performance environment where the action frequently extends beyond the lip of the stage and in which the presence of the audience is at various times acknowledged both implicitly and explicitly, the very notion of an 'aside' is nicely problematised. The rehearsal notes for The Jew of Malta indicate that one such issue arose at an early stage. Lacking access to a full, editorialised script, actors very often have to deduce which of their scene partners' lines are in fact asides, and this can only be done in group rehearsal. McCarthy records a conversation between John Harrell ( $\mathrm{JH}$, playing Ithamore), and Benjamin Curns (BC, playing Pilia-Borza) that reveals an interesting question about how parts can conceal important formal considerations such as playing styles:

$\mathrm{JH}$ and $\mathrm{BC}$ had a brief conversation about the nature of asides. $\mathrm{JH}$ suggested that an ostentatious gesture could be used to indicate asides so that not only the audience but the actors know when something isn't supposed to be heard. When BC, as PiliaBorza, says, 'What shall we do with this base villain, then?' JH has no way of knowing that Ithamore isn't supposed to hear that. It's only through rehearsal that actors can discover these things. JH thus suggested that large and obvious gestures to indicate asides would have been useful to early modern [actors] with limited rehearsal times. For the same reason, he wondered if they might be useful to Actors' Renaissance Season actors. ${ }^{25}$

\footnotetext{
${ }^{25}$ McCarthy, 'Brief Introduction,' 8.
} 
What John Harrell $(\mathrm{JH})$ seems to be suggesting in this instance is that limited group rehearsals do not necessarily result in performance choices that are largely improvised and that narrative clarity is not necessarily enhanced by choices that are fluid in this way. Rather, the practical impulse of the actor in this situation is to fix, rather than to leave fluid, a choice that could have a direct effect on narrative clarity. The impulse to indicate and codify the form of the aside, rather than improvise this mode of direct address to the audience, will tend to define and fix the ways in which the actor deals with the audience in productions rehearsed under these conditions. A consideration of form is therefore not entirely absent from this process.

Harrell's proposition that the Jew of Malta company adopt a repeatable gesture as a convention when delivering asides is an interesting and pragmatic proposition to give shape to a production, quickly and cleanly. The question of how to deal with and address the audience is one that the Actors' Renaissance Season productions have needed to answer since the project's inception. The cumulative experience of the Sharers is beginning to find solutions.

How to interact with the audience is an issue that is more fully addressed by the ASC's resident and touring productions of Shakespeare in ways that may also inform the Actors' Renaissance Season. 'Direct Audience Contact' is a phrase coined by actors at the ASC to describe its Shakespearean house style and this concept is described in some detail to audiences for the resident and touring company productions during the detailed preshow announcements. Opportunities are seized to address the audience to an extent that it becomes a dominant, almost default, mode of performance. The longer rehearsal periods and much longer performance runs for the resident and touring productions allow actors such as John Harrell to develop nuanced characterisations through improvisation, in 
performance choices that actively engage the audience in the very process of characterisation itself. This instinct to characterise rather than perform in front of the audience - added to Harrell's familiarity with the space and audience at the Blackfriars - has informed his work with obscure, archaic or otherwise theatrically-problematic language. Harrell's Shakespearean characters reveal themselves through their transactions with the audience: he cast the audience as (for instance) personal acolytes, intellectual inferiors and 'those in the know' for Holofernes' Latin excursions in Love's Labour's Lost. Harrell's preparations during rehearsals allowed for a wide range of possible transactions with the audience and the choices he made on a 'beat-by-beat' basis kept the audience actively engaged in an evolving relationship with his character, one which nicely side-stepped the issue of whether the meaning of the Latin text could be understood.

Archival recording of productions from the first few Actors' Renaissance Seasons would suggest that actors felt less comfortable engaging with audiences during performances of these plays than the Shakespeare plays performed in the main season. A recent study of the Actors' Renaissance Season production archive made for this chapter found that audience engagement performance strategies in Actors' Renaissance Season productions are surprisingly limited in scope, outside of conventional soliloquies or asides. ${ }^{26}$ Where these modes of direct address do occur, the audience-engagement tactics used rarely develop beyond an equally conventional use of 'audience as confidantes':

[Actors' Renaissance Season] actors seem most comfortable speaking to each other unless they are alone onstage or otherwise disengaged from the other characters in a scene. Speaking directly to the audience almost always happens in a separate

\footnotetext{
${ }^{26}$ Jemma Levy, a postgraduate student in the MLitt./M.F.A. programme at Mary Baldwin College, examined the Actors' Renaissance Season production on my behalf and I am indebted to her work in this regard.
} 
time/space. They seldom manage to successfully intertwine speaking with the audience and speaking with each other...in general, the audience is very rarely transformed into something other than what they are: observers of the story. ${ }^{27}$

This might be a result of recordings being made early in the run, before actors have been able to experiment with their audiences; another possibility is that when learning lines from a part, an actor won't necessarily always know at a glance what is a soliloquy intended as an explicit address to the audience and what is a monologue forming part of a larger dialogue with others on stage at the time. Therefore, strategies to engage the audience in these moments might well be postponed, pending further investigation in group rehearsals. I would argue that a combination of these two factors might very well result in performances that infrequently use the audience with real agency.

It has been my experience that the inclination to invest such agency in audiences develops over time, in actors who are confident in their roles. Bridget Escolme describes very similar qualities in Mark Rylance's Hamlet, at Shakespeare's Globe in 2000, a performance which drew on his work in the same role for the RSC twelve years earlier. Escolme argues that Rylance's transactions with the audience craft a kind of subjectivity that is at once Rylance and Hamlet. ${ }^{28}$ To attempt to compare a performance nurtured through two significant productions over twelve years with any developed over fifty-five hours and performed over less than three months would be unfair and faintly ludicrous. But I would like to suggest that, of all the elements comprising this celebrated and iconic performance,

\footnotetext{
${ }^{27}$ Levy, Jemma. Email interview, Mar. 2010.

${ }^{28}$ Escolme, Bridget, Talking to the Audience: Shakespeare, performance, self (Abingdon: Routledge, 2005) 6273.
} 
among the most significant are Rylance's security in and familiarity with the role and the space, added to his ongoing experience addressing the visible audience at the Globe.

\section{The pressure of time, and the trouble with Shakespeare}

Taken as a whole, the Actors' Renaissance Season's emphasis on private study, memorisation of 'parts,' and an expedited rehearsal period produces approaches to characterisation that need to be judged in a different light to those prepared with the benefit of time and the constant outside eye of a director. In the Actors' Renaissance Season, broad stroke characterisation is a place to begin from during private study of a part. With only a week of group rehearsals, it is frequently where the performances begin, too. Throughout Making Shakespeare, Stern argues persuasively for an early modern view that conflates our modern understanding of 'character' and 'type,' while John Harrell admits that there is a danger some critics will find Actors' Renaissance Season productions 'overly comical, even grotesque. ${ }^{29}$ The expedited rehearsal period places considerable pressure on the actors to commit to performance decisions and choices that under different circumstances they might be tempted to postpone, pending further exploration. James Keegan also notes the challenge of bringing a consistent quality of performance out of a reduced period of rehearsal:

I will not pretend that I don't have anxiety about the Renaissance season and the product that comes to the stage. That I concern myself as an actor frequently (I hope I do) with precision. I think building a character in a scene is a matter of being precisely aware. I think that sometimes in the speed of the Renaissance season, the

\footnotetext{
${ }^{29}$ Harrell, John, Personal interview, Oct. 2010.
} 
scene is not always served. And if the scene is not served, the play, ultimately, is not served. So I do have anxiety about the Renaissance season being seen as 'experimental' or, perhaps, not being seen that way. About somebody coming into the house and saying, 'What kind of a thing is that?' Is it what, at a professional level, we should be producing ${ }^{30}$

But the growing general audiences who attend these productions seem to enjoy these performances, especially when they are fast and funny and, Harrell suggests, not famously Shakespearean:

I like to believe that audiences coming to see, for example, The Blind Beggar of Alexandria (2009), have no expectations except entertainment. It's probably little more than simple paranoia, but I sometimes dread performing a play like Hamlet (2009) because I fear an audience is only there to have its preconceptions of the play ratified, and my performance can only let them down. ${ }^{31}$

Since preconceptions of this particular kind are not typically a factor in ASC audiences' responses to the productions of plays by Ben Jonson, Harrell emphasises what he sees as Jonson-specific requirements for speed and plot clarity:

Though we've done work by a variety of Shakespeare's contemporaries, the only one I think I would recognize in a dark alley is Ben Jonson. I've now been in Eastward, Ho, The Devil is an Ass, Volpone, and The Alchemist. In most of these I've played Jonson's

\footnotetext{
${ }^{30}$ McCarthy, 'Brief Introduction,' 25.

${ }^{31}$ Harrell, Personal interview, 2010.
} 
main con artist, and l've found that his work demands a couple of things that Shakespeare mainly does not. The first of these is a thorough familiarity with plot. That is to say that most of these comedies involve a con man and his helper keeping many subplots afloat at once. In order to keep a performance straight, in the most pedestrian what-comes-next sense, l've needed a far more thorough reading of the play than I have with any of the Shakespeare leads that I've played. ${ }^{32}$

Harrell's 'thorough reading of the play' is nicely complicated by the rehearsal technique adopted for plays in the Actors' Renaissance Season. As suggested above, the absence of group text work in rehearsals places a disproportionate level of responsibility for narrative clarity on the actor with the most lines. Placed in this position, Harrell clearly relishes the attendant responsibilities:

I think that an actor serves Jonson best by cracking his lines off almost faster than an audience can absorb them, and for the con men, certainly faster than any of the marks can react to them. What this requires from an actor is a familiarity with lines that puts them well beyond whatever bit of the brain summons the next metaphor in Hamlet. I find performing Jonson in this way to be exhilarating, nearly improvisatory, and satisfactorily physical. ${ }^{33}$

Harrell's performances in plays by a range of early modern playwrights seem to share a commitment to the commonly held view that audiences neither need nor desire a literal understanding of archaic, obscure or otherwise difficult portions of text. Harrell's ability to 32 Ibid.
${ }^{33}$ Ibid. 
cast the audience in a range of roles is a hallmark of his work at the Blackfriars, and here he chooses the same basic action for both his audience and his scene partners (the 'marks') onstage. What Harrell's performances tell us about early modern theatre in a more general sense is that attention to narrative development and characterisation through actions reaching beyond the lip of the stage can result in an inclusive experience for the audience, regardless of whether that audience is already familiar with the play.

The scholarly reception of the Actors' Renaissance Season plays has been enthusiastic. As a result, the ASC's profile within the academy has been enhanced beyond its bold architectural statement, the Blackfriars Playhouse reconstruction. The American Shakespeare Center can now boast a sizeable contribution to the production history of plays by a wide range of early modern playwrights, from Marlowe, Webster and Middleton to the anonymous presence behind Look About You (one of the 2011 Actors' Renaissance season offerings). Increasing numbers of plays by early modern playwrights other than Shakespeare are finding their way into the season planning for the resident company, no doubt the direct result of the success of the Actors' Renaissance Season.

The successful formula in which plays by 'other' early modern playwrights are approached first and foremost as entertainment, avoiding some of the expectations that an audience for a well-known Shakespearean title arguably brings with them, is likely to be continued. As Harrell explains:

The main thing that unfamiliar plays offer an audience is the possibility of genuine surprise. In my capitalist opinion, surprise is the main commodity that people are 
trying to buy with their entertainment dollar, or at least is the one that I am most interested in selling. ${ }^{34}$

In recent years, ASC has shifted its marketing language for early modern plays by playwrights other than Shakespeare moving on from metaphors of salvage attached to oneoff staged readings - in the Education department's 'Bring 'Em Back Alive' series - to images of rebirth and creativity, as in the 'Actors' Renaissance Season.' I wonder if yet another name-change will one day be necessary for the American Shakespeare Center if its work on 'other' playwrights of the period is ultimately judged its most significant.

Non-Shakespearean Early Modern titles performed in the Actors' Renaissance Season to date:

2005: The Tamer Tamed, A King and No King

2006: Tis Pity She's a Whore, Eastward Ho!

2007: The Duchess of Malfi, The Devil is an Ass

2008: Volpone, The Jew of Malta, The Witch

2009: The Revenger's Tragedy, The Changeling, The Blind Beggar of Alexandria

2010: The Malcontent, Look About You, A Trick To Catch The Old One

\section{Acknowledgements and influences:}

The chapter makes use of primary evidence from the rehearsal room, archive tape, and not a few horses' mouths. The chapter draws extensively on Ryan McCarthy's

${ }^{34}$ Ibid. 
unpublished MFA thesis from Mary Baldwin College, which contains an account of the rehearsal process for 2008 Actors' Renaissance Season production of The Jew of Malta. ${ }^{35}$ Another Mary Baldwin College postgraduate student, Jemma Levy, ably assisted me with research in the ASC production archive, and this work was made possible by the University of Birmingham's Research and Knowledge Transfer Fund. Dramaturgs Raven Claifin, Christine Parker and Justin Schneider provided points of clarification and valuable insight, as did my colleague Dr. Paul Menzer, Director of the Mary Baldwin College MLitt/MFA programme. Cassie Ash, research student at The Shakespeare Institute and Mary Baldwin College alumna, was kind enough to give me feedback on a draft of this chapter, and so any errors are entirely my own.

My greatest debt is to those ASC actors who have shared their insights and experiences with me over the course of the three ASC productions I have directed (for the touring and resident seasons) and several interviews, particularly John Harrell and Chris Johnston. Working with and observing actors over the last decade or so has been the way I have developed and tested ideas about early modern drama in performance, and while I admit this position is difficult to defend as objective, it has the considerable advantage of being tested on a regular, practical, and ongoing basis, by the people I respect the most.

\footnotetext{
${ }^{35}$ Ryan McCarthy is one of several postgraduate students from the Mary Baldwin College MLitt./MFA programme to have served as dramaturg on ARS season productions in recent years, observing and sometimes recording rehearsals, and offering feedback when prompted to do so. Scholars with an interest in rehearsal records for the Actors' Renaissance Season will find this, and other unpublished MFA theses in the Mary Baldwin College library catalogue, of particular use.
} 